\title{
THE LIMITS TO ADAPTATION IN RESTORED ECOSYSTEMS AND HOW MANAGEMENT CAN HELP OVERCOME THEM ${ }^{1}$

\begin{abstract}
Adaptation drives the diversity of form and function observed in nature and is key to population persistence. Yet, adaptation can be limited by a lack of genetic variation, trade-offs, small population size, and constraints imposed by coevolving interacting species. These limits may be particularly important to the colonizing populations in restored ecosystems, such as native prairies restored through seed sowing. Here, we discuss how constraints to adaptation are likely to play out in restored prairie ecosystems and how management decisions, such as seed mix composition, prescribed fire, and strategic site selection, might be used to overcome some of these constraints. Although data are still limited, recent work suggests that restored prairie populations likely face strong selection and that promoting the potential for adaptation in these systems may be necessary for restoring populations both now and in the face of further global change.
\end{abstract}

Key words: Contemporary evolution, ecological restoration, genetic diversity, rapid adaptation.

Adaptation may be necessary for populations to establish and persist in novel environments, particularly in our current era of human-dominated environmental change (Davis et al., 2005; Jones \& Gomulkiewicz, 2012). Yet, adaptation is not guaranteed and questions remain over whether adaptation will occur fast enough to rescue populations in rapidly changing environments (Bürger \& Lynch, 1995; Gomulkiewicz \& Shaw, 2013; Carlson et al., 2014). Over 40 years ago, Antonovics presented a seminal work on the limits of natural selection (Antonovics, 1976) at the 22nd Annual Symposium at the Missouri Botanical Garden. Here we revisit those limits from an applied perspective.

The idea of applying evolution to solve practical problems is not new. Humans have relied on artificial selection for millennia as we domesticated crops and animals. In recent decades, a growing awareness among ecologists that evolution can occur rapidly (Palumbi, 2001; Hairston et al., 2005; Schoener, 2011) has initiated new discussions on the potential for capitalizing on evolution to solve practical agricultural and ecological problems (Hendry et al., 2011; Sgrò et al.,
2011). In this review, we apply that knowledge to ecological restoration, specifically to prairies restored through seed sowing. We first review literature and present new data suggesting why rapid adaptation may be necessary in restored prairies and then summarize a new case study illustrating that rapid adaptation can, but may not always, occur. We then discuss potential constraints to adaptation in restored prairies, and conclude by discussing how restoration actions during prairie restoration may hinder or promote adaptation. Because rapid adaptation in restored populations may be necessary to ensure population persistence both now and in the face of further environmental change, understanding when populations may fail to adapt and how to overcome constraints to adaptation may be foundational to promoting restoration success.

\section{The Importance of Rapid Adaptation in Restoration}

Rapid adaptation may be particularly important to ecosystems established through seed sowing, a common practice during grassland restoration including prairies, owing to dispersal limitation of focal plant populations

\footnotetext{
${ }^{1}$ We thank Bill Schneider and an anonymous reviewer for providing thoughtful feedback on an earlier version of this manuscript and the organizers, speakers, and attendees of the 65th Annual Syposium at the Missouri Botanical Garden for numerous thoughtful comments that helped refine the ideas presented here. This work was funded by National Science Foundation (NSF) DEB-1547961 awarded to J. A. L. and L. A. B. and by NSF DDIG DEB-1701791 awarded on behalf of S. M. M. to J. A. L.

2 Indiana University, Department of Biology and the Environmental Resilience Institute, Jordan Hall, 1001 E. 3rd Street, Bloomington, Indiana 47405, U.S.A.

3 Michigan State University, W. K. Kellogg Biological Station, 3700 E Gull Lake Drive, Hickory Corners, Michigan 49060, U.S.A.

4 Michigan State University, Department of Plant Biology \& Ecology, Evolution, and Behavioral Biology Program, Plant Biology Laboratories, 612 Wilson Road, East Lansing, Michigan 48824, U.S.A.

5 University of Minnesota, Department of Ecology, Evolution, and Behavior, 140 Gortner Laboratory, 1479 Gortner Avenue, St. Paul, Minnesota 55108, U.S.A.

* Author for correspondence: jenlau@iu.edu
} 
(Bakker \& Berendse, 1999; Török et al., 2011; Grman et al., 2014). Most such restorations involve introducing populations to novel environments. By definition, restorations are installed on degraded lands (Suding, 2011), including active or former agricultural fields supporting successional grasslands, and typically result in novel assemblages of plant and animal communities (Benayas et al., 2009; Hobbs et al., 2009). In most situations, the target-restored community has not been present at the site undergoing restoration for decades or centuries, and in some cases, sites are not even restored to the pre-degradation ecosystem type. For example, in a study of 29 restored prairies in Michigan (Grman et al., 2014), all were established in areas historically supporting forest and savanna, not prairie, prior to agricultural land use (Grman \& Brudvig, unpublished data). Additionally, even in cases where lands are restored to their historical community type, the land uses immediately preceding restoration may have altered ecosystem properties, such as soil attributes, hydrology, or components of biodiversity (e.g., soil microbial communities) (Koziol et al., 2018). For example, soils with a history of tillage agriculture can support persistent differences in soil properties (e.g., elevated soil phosphorus, depleted soil organic matter, reduced waterholding capacity), compared to soils with no history of tillage (e.g., McLauchlan, 2006; Brudvig et al., 2013).

Additionally, despite emphasis on using local seed, the evolutionary history of sown seeds may be a poor match for the restoration site conditions for several reasons. Seeds used to establish a restoration are usually produced by commercial seed companies propagating seeds originally collected from remnant areas or are field-collected seeds from remnant fields or other restored prairies. As discussed above, restoration site conditions may differ, perhaps dramatically, from conditions supporting nearby seed sources owing to the history of disturbance at a restoration site. Second, disturbance history aside, local adaptation may occur on a very fine geographic scale, resulting in source seed populations even from nearby locations being poorly matched to the restoration site environment (McKay et al., 2005; Vander Mijnsbrugge et al., 2010; Richardson et al., 2014), although local adaptation is most consistently detected at larger spatial scales (Leimu \& Fischer, 2008). Finally, evolutionary change may occur through the processes of seed harvesting and propagation (McKay et al., 2005; Vander Mijnsbrugge et al., 2010; Dyer et al., 2016; Gallagher \& Wagenius, 2016; Ensslin et al., 2018), potentially yielding source populations that are poorly adapted to diverse, multi-species communities. For all of these reasons, sown prairie populations may initially be poorly adapted to local restoration conditions.
Consistent with the hypothesis that restored prairie populations may be poorly adapted to conditions at the onset of restoration, there is substantial variation in the establishment success of many prairie taxa. In a study of 29 prairies in southwest Michigan, only 14 of 133 studied species successfully established in $100 \%$ of prairies in which they were sown; most other species exhibited substantial variation in establishment success (Grman et al., 2015). This variation may result because conditions at sites undergoing restoration are inappropriate for the species in general (i.e., outside the species niche); however, variation in establishment among sites also may depend on the particular ecotype or population sown and result from genotype $\times$ environment interactions. Genotype $\times$ environment interactions (i.e., situations where the "best" population in terms of fitness varies across environments) are ubiquitous (Bradshaw, 1965; Des Marais et al., 2013), and they likely occur within restorations as well (e.g., Gallagher \& Wagenius, 2016). For example, we sowed six seed sources of the annual plant Chamaecrista fasciculata (Michx.) Greene in 12 restored prairies, and detected significant genotype $\times$ environment interactions on plant size $\left(\mathrm{F}_{55,1129}=1.87, P<0.0002\right.$, Fig. 1). While some source populations never produced particularly large individuals, other source populations performed exceptionally well at some sites but poorly at others. These genotype $\times$ environment interactions were observed across an extremely small spatial scale-all study sites are within $3.1 \mathrm{~km}$ of one another.

The genotype $\times$ environment interactions described above indicate that a single seed source is not optimal for all prairies even within a small region and that some subset of populations (if not the vast majority) may not be well adapted to local site conditions. As a result, in the absence of (or perhaps even in spite of) meticulous matching of seed sources to restoration sites, rapid adaptation may be necessary for successful population establishment, growth, and persistence.

Rapid adaptation certainly can occur in restorations. We capitalized on an experiment in which two prairies $15 \mathrm{~km}$ apart were sown using identical methods and seed sources in 2010 . Fortunately, original seeds were saved and could be resurrected and included in a common garden study along with field-collected seeds from each of these prairies six years later. Chamaecrista fasciculata (a native annual legume) populations collected from the restored prairies had genetically diverged from the original source population in several traits (e.g., flowering time, root nodule production, and specific leaf area; Fig. 2; Magnoli, 2018). These evolutionary changes seem to have resulted in local adaptation at one of the sites, and this local adaptation increased estimated population growth rate, although lambda remained below one even in the locally adapted 


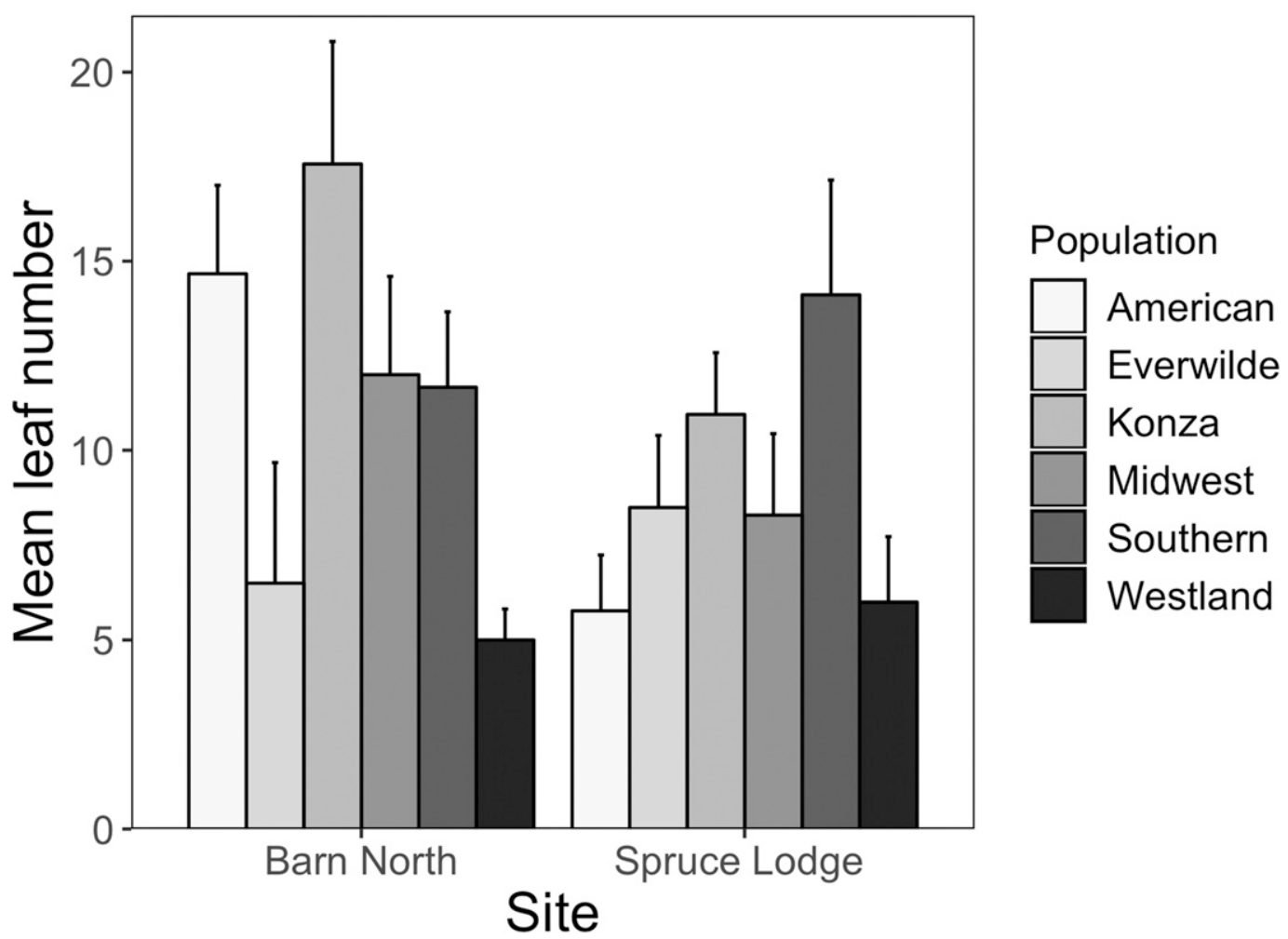

Figure 1. Six Chamaecrista fasciculata (Michx.) Greene source populations were sown into common gardens nested within 12 establishing prairies at Kellogg Biological Station, Hickory Corners, Michigan. Significant genotype $\times$ environment interactions were detected on plant size traits (leaf number), and the size of each source population grown at two illustrative sites is shown here. Population relative performance varied across sites. For example, population "American" produced many leaves at Site "Barn North," but produced among the smallest plants at Site "Spruce Lodge."

population in the year of study (Magnoli, 2018). This work also highlights that local adaptation may not always occur during restoration. In the second study site, the local restored population performed no better than either the other restored population or the original source seeds (Fig. 2), begging the question: Why do restored populations appear to exhibit rapid adaptation in some cases but not in others? Only by understanding the limits of natural selection can this question be answered and approaches developed to overcome those limits.

The Limits to Natural Selection and How They Apply to Restoration

Antonovics (1976) framed his discussion on the limits to natural selection around the constraints acting on marginal populations. Most restored populations may face many of the same challenges of marginal populations, including (1) lack of genetic variation, (2) tradeoffs, (3) small population size, and (4) coevolutionary constraints. Antonovics wrote his paper shortly after the advent of gel electrophoresis revealed large amounts of genetic variation in nature, and as a result, he discounted the classic explanation of lack of genetic variation for inhibited evolutionary responses in natural populations. Yet restorations are not natural populations and may sometimes be limited by genetic variation. First, seeds used in restorations typically come from two sources: commercial seed companies actively propagating prairie plants for seed and field collections from remnant or restored populations. In both cases, genetic diversity may be reduced compared to natural populations (e.g., Williams \& Davis, 1996, but see Reynolds et al., 2012). In the case of commercial seed companies, little may be known about the origins or diversity of commercial populations (Kramer et al., 2019), but if the initial seed source was a small sampling of individuals (especially if from a small or inbred remnant population or other restored populations that may have experienced demographic bottlenecks during establishment), then genetic diversity may be substantially reduced compared to large natural populations. Many commercial seed sources are admixed populations resulting from initial collections from many natural populations within a region, which may help alleviate this potential 


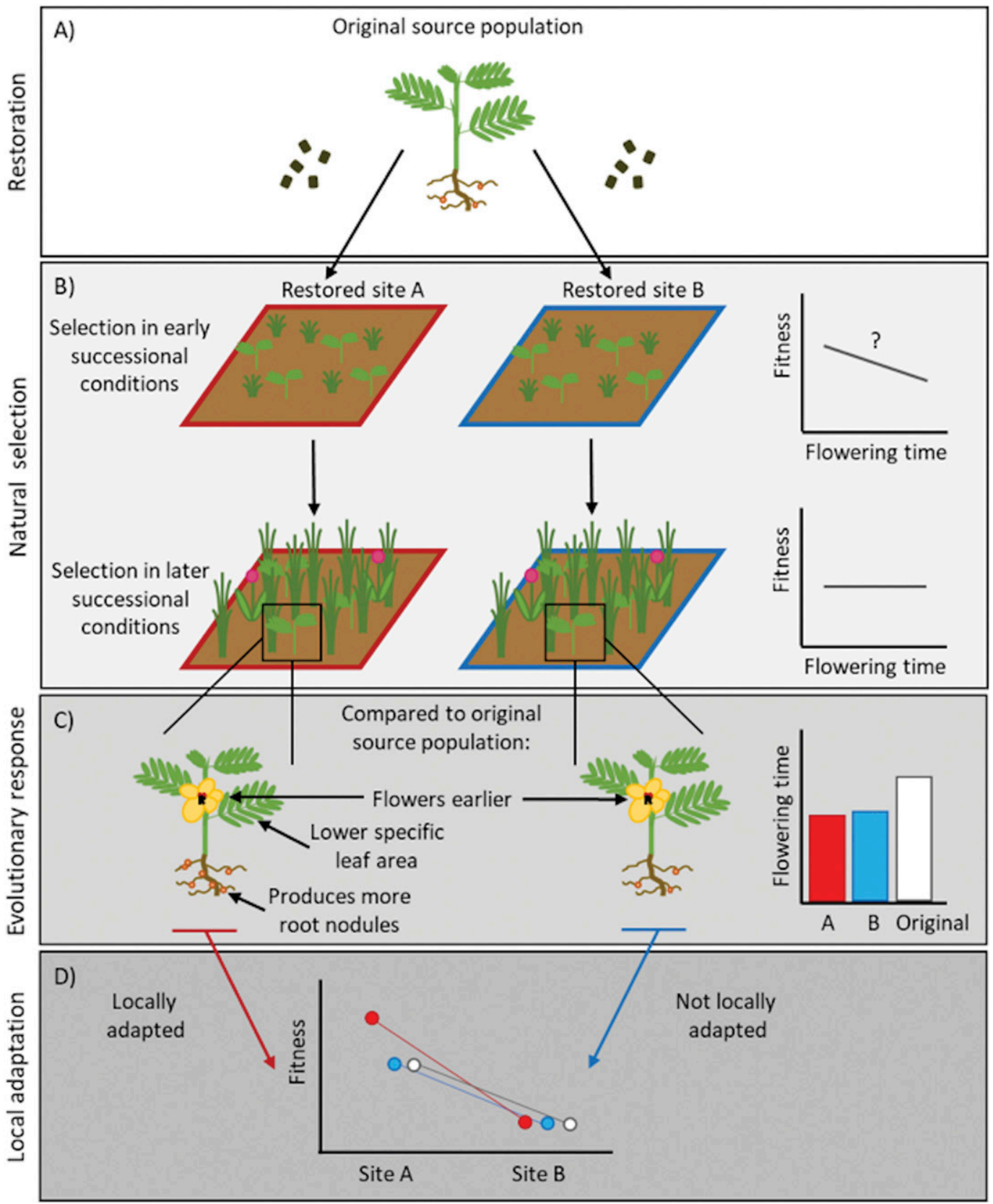

Figure 2. - -A. Chamaecrista fasciculata (Michx.) Greene seeds from a single source population were sown as part of a prairie seed mix into two former agricultural fields approximately $15 \mathrm{~km}$ apart in southwest Michigan. - B. Chamaecrista fasciculata experience selection under early successional conditions (the first three to four years after seeding) and under later-successional conditions as the prairies mature. Selection was estimated on a suite of traits (including flowering time) on both populations six years after seeding. - C. Plants from populations evolving in site A or site B and the original source population were grown in common environments (the two restoration sites) and traits were measured to examine evolutionary changes in the restored populations. - D. Fitness estimates from a reciprocal transplant between the two sites show that population A has adapted to its home site while population B has not.

concern (Bucharova et al., 2019). Additionally, it is possible that selection during seed harvesting or cultivation of agronomically propagated populations ("unconscious selection" sensu McKay et al., 2005) reduces genetic variation, particularly if selection in cultivated fields or selection imposed by harvesters 
selects against traits that are advantageous in the more complex, high-diversity environments of restored prairies (Vander Mijnsbrugge et al., 2010; Dyer et al., 2016). For example, a study of 72 herbaceous species documented a loss of seed dormancy in populations propagated in a botanical garden compared to wild populations, at least for short-lived species (Ensslin et al., 2018). While this study could not definitively attribute the observed dormancy differences to evolutionary responses to cultivation because maternal effects were not controlled for, it does suggest the potential for ecologically important phenotypic (and possibly genetic) changes during cultivation. Commercial seed nurseries are aware of these challenges, however, and may collect from as many individuals as possible from large populations throughout the season and over multiple years and stratifying collected seed to promote germination and maintain the diversity collected (Bill Schneider, pers. comm). Simultaneously, current recommended best practices for seed production outline several methods for reducing evolutionary changes during selection, including minimizing the potential for selection and limiting the number of generations that populations are propagated (i.e., restarting cultivations from wildcollected seeds frequently) (Basey et al., 2015).

In the case of field-collected seeds, when propagules are collected from restored (rather than natural) populations, the outcome may be seeds that have gone through multiple demographic bottlenecks reducing effective population sizes and genetic variation. In other words, the seeds in the restored population used for collection are a subset of those planted representing the genotypes that perform best at that particular site. Collection from natural populations may face similar hurdles given that many remnant populations may be small in size, isolated, and as a result, susceptible to historical bottlenecks, leading to random genetic drift and potentially inbreeding depression (Honnay \& Jacquemyn, 2007). Furthermore, if seeds are collected during a single sampling event (either from a restored or natural population), they likely represent a subset of the population. For example, when seeds are collected only in a single year, those seeds may represent the genotypes best able to reproduce in that particular year. Similarly, when seeds are collected only during a small timeframe within a growing season, they are likely a subset of the populations with a particular phenology, potentially reducing the amount of genetic variation in flowering or fruiting time and correlated traits (Dyer et al., 2016). In sum, the very methods used to collect and select the seeds used to sow restored prairies may cause reduced genetic diversity that could limit adaptation.

Trade-offs result when the direction of selection on traits is opposed by the genetic covariance between those traits. For example, in Etterson and Shaw's (2001) now classic study investigating adaptation to global warming, leaf thickness was positively correlated with leaf number and because selection favored plants with thinner but more leaves, this positive correlation opposed the direction of selection and reduced the magnitude of evolutionary response (Etterson \& Shaw, 2001). In fact, in their study, these adverse genetic correlations between traits limit the ability of the studied plant populations to adapt to global warming. While such constraints may not necessarily be common and while the effects of such trade-offs may be reduced over longer timescales as strong selection antagonistic to the direction of the correlation can erode these constraints (reviewed in Conner, 2012), genetic correlations sometimes may limit the short-term responses characteristic of rapid adaptation in restored populations. For example, if rapid growth is highly advantageous for establishment but is negatively correlated with anti-herbivore defenses (i.e., the classic growth-defense trade-off: Herms \& Mattson, 1992; Züst \& Agrawal, 2017), then the evolution of fast growth may be constrained in restored ecosystems experiencing high herbivory. Few studies measure selection in restored populations so it is unclear how often trade-offs are likely to constrain adaptation. In two studies to date, genetic covariances detected in the restored Chamaecrista fasciulata populations in Magnoli (2018) were relatively small and unlikely to constrain evolutionary responses, and Kulpa and Leger (2013) detected covariances that were in the same direction as selection rather than opposing selection and, therefore, would accelerate evolutionary responses.

Small population size may constrain adaptation for a number of reasons, including increased swamping effects of gene flow from surrounding populations, limited likelihood of possessing appropriate genetic combinations, increased importance of genetic drift, and increased likelihood of extinction (Antonovics, 1976; Willi et al., 2006). Indeed, local adaptation is much more commonly reported in large ( $>1000$ individuals) populations compared to smaller populations (Leimu \& Fischer, 2008), and in Magnoli's (2018) study of Chamaecrista fasciculata highlighted above (Fig. 2), local adaptation was only detected in the population that was three times larger (based on geometric mean population size). Yet, in most restorations and particularly largescale restorations $>10$ ha, many of the effects of small population size may be minimal for most taxa for several reasons. First, given that up to $99.9 \%$ of prairie habitat has been lost in North America (Samson \& Knopf, 1994) and that existing remnants and restored populations are often small in size and spatially isolated, swamping effects of gene flow are likely minimal in most locations. Second, large amounts of seed can be sown and this may result in large population sizes, particularly if rates of 
establishment are high. However, this may be less true for the rarer, more expensive species, more difficult-toestablish taxa, or even taxa that easily establish at most but not all sites. For example, estimated population sizes based on seedling surveys (ten $5 \times 5 \mathrm{~m}$ plots located along transects through the center of each site) of five early establishing, apparent forbs that were sown into the 12 restored prairies discussed in Figure 1 often exceeded 1000 individuals per site, but four of these taxa also exhibited extremely small population sizes $(24$ to 86 individuals) in at least one site (median population size: Chamaecrista fasciculata $=1306$, Coreopsis lanceolata $=828$, Echinacea purpurea $=2259$, Ratibida pinnata $=625$, Rudbeckia hirta $=1075$; note that these values may be underestimates given that additional sown seeds could potentially germinate in later years). However, more than population density, the key metric in determining the relative importance of drift versus selection is effective population size. As discussed above, the effective population size (and genetic variation) could still be small even if population density is large, due to low genetic diversity within seed sources or within established populations, given the potential for bottlenecks of even genetically diverse seed mixes during establishment.

Finally, Antonovics (1976) presented the idea of coevolutionary constraint-that coevolving species interactions may slow adaptation to a novel environment or during range expansion. Although how coevolution results in a constraint to adaptation is not entirely developed in Antonovics (1976), recent hypotheses have emerged. For example, Strauss (2014) argues that some of the success of invasive species may be due to escape from genetic constraints imposed by the large number of strongly interacting species in the native range. While limited data support this hypothesis, one study detected evidence that a preponderance of strong negative correlations between traits mediating plant interactions with different types of herbivores could slow the rate of evolutionary response by $60 \%$ (Wise \& Rausher, 2013). Perhaps restored populations may be less affected by such coevolutionary constraints given that they are often isolated and may escape some herbivorous or pathogenic antagonists at least early during the colonization process. However, coevolutionary interactions with competing plant species, whether sown or weeds, could also constrain adaptation either because of genetic trade-offs between competitive abilities with different types of competitors (as in the herbivores in Wise \& Rausher, 2013) or because high-diversity restored prairies may be more likely to include a strong competitor by chance that reduces population sizes of other species and available ecological niche space (discussed in Kleynhans et al., 2016; see also de Mazancourt et al., 2008).

\section{Management Approaches for Overcoming the Limits} of Natural Selection

Some of the limits to natural selection discussed above may be exacerbated in restored ecosystems (lack of genetic variation), and others like trade-offs and coevolutionary constraints may depend on specific restoration conditions. Nevertheless, aspects of the restoration process may be tailored to help minimize some of these constraints. Here we focus on several strategies that may be particularly effective at minimizing constraints due to lack of genetic variation, the constraint we suspect is most likely to be particularly problematic in prairie restorations. These strategies include: (1) using genetically diverse seed mixes, (2) sowing large seed densities of hard-to-establish taxa (although this can often be cost-prohibitive) and implementing other strategies to promote establishment, and (3) engaging in management activities that promote reproduction and gene flow and, therefore, the maintenance of genetic variation. We focus on prairie restoration from a de-vegetated starting condition (a tilled agricultural field or old field sprayed with herbicide), whereby seeds of native prairie species are sown once to initiate the restoration (Grman et al., 2014). The restoration planting then undergoes succession to dominance by prairie species, typically over the course of three to four years (Grman et al., 2013), and is managed by periodic fire and other prescribed disturbances, such as mowing.

\section{GENETICALLY DIVERSE SEED MIXES}

Ensuring genetically diverse seed sources requires careful initial seed collection and propagation, including beginning with a large population size sampled over the fruiting season (or ideally multiple seasons) and minimizing selection during propagation (McKay et al., 2005; Vander Mijnsbrugge et al., 2010; Basey et al., 2015; Dyer et al., 2016). The propagation conditions may exert strong selection, potentially favoring traits that are maladaptive in the restorations. For example, raising prairie seeds under agronomic conditions (e.g., high nutrient availability, high disturbance, low diversity) can sometimes select for altered resource allocation (e.g., reduced inflorescence production but increased biomass production; Nagel et al., 2019) or germination timing (Schröder \& Prasse, 2013), although in other cases limited evolutionary changes might be observed (Nagel et al., 2019). Such traits are unlikely to be advantageous in the restored prairie planting, and if selection is strong, genetic variation in these and other traits could potentially be reduced (although the few studies to date have failed to find evidence for this phenomenon, Aavik et al., 2012) or particular alleles 
may be lost (Nagel et al., 2019), reducing the capacity for the population to evolve increased nutrient-use efficiencies and competitive abilities over the course of the restoration.

Selection also can occur as the seeds establish in the restored planting and this may further reduce genetic diversity. The strength of this selection may be reduced by sowing seeds of well-adapted genotypes, although this may be challenging to predict given nascent understanding about the spatial scale of local adaptation for many species (McKay et al., 2005; Vander Mijnsbrugge et al., 2010). A common recommendation to minimize selection early during the restoration process is to use local seed sources from similar environments (McKay et al., 2005; Rowe \& Leger, 2012; Basey et al., 2015); however, in one of few studies to date, exceptionally strong selection even was detected on populations restored with local seed sources (Kulpa \& Leger, 2013). One could potentially go further, though, by choosing seed sources that would improve establishment outcomes in the face of many common challenges to restorations and potentially even choosing seeds that combat those challenges. For example, prairie plants sown from seeds during restoration face intense competition from weedy native and exotic species during establishment (Norton, 2009; Matthews \& Spyreas, 2010). Interestingly, in one example, seeds collected from heavily invaded populations were both more tolerant of competition from invasive species and actually reduced the growth of the invasive species (Rowe \& Leger, 2011). Selectively using such populations may both enhance establishment, thereby preserving genetic variation, and inhibit invasive species.

While careful seed collection and propagation can help minimize potential genetic diversity effects in restoration, a more powerful option may be to use hyper-diverse seed mixes, including seeds from multiple natural populations, possibly even across geographic regions (Lesica \& Allendorf, 1999; Rice \& Emery, 2003; McKay et al., 2005; Broadhurst et al., 2008; Breed et al., 2013). This approach should increase genetic variation (Fig. 3) and may have the added benefit of helping to overcome trade-offs that have been historically maintained by selection within individual populations and can slow evolutionary responses. Trade-offs can be broken as novel trait combinations arise from recombination. Admixture resulting from sowing a diversity of seed sources may also lead to heterosis, where deleterious alleles are masked in the offspring of previously isolated populations, which can provide a transient increase in population fitness that may increase the likelihood of establishment (Rius \& Darling, 2014). The benefits of admixture have been highlighted as a potential mechanism of invasive species success (Ellstrand \& Schierenbeck, 2000; Rius \&
Darling, 2014) and have been associated with increased persistence of other translocated plant populations (Godefroid et al., 2011) and for similar reasons may benefit restored populations. Although some risks have been identified with combining genetically isolated populations and including non-local seed sources (e.g., outbreeding depression) (reviewed in Bucharova et al., 2019), the benefits may strongly outweigh the risks if adaptation is necessary for successful establishment and/or population persistence in the face of future environmental change, including the predicted increase in severity and frequency of extreme climatic events (Prober et al., 2015). A more nuanced approach, using multiple populations within a single region ("regional admixture"), might effectively balance potential costs and benefits (Bucharova et al., 2019) and is consistent with recommendations based on theoretical predictions suggesting that the likelihood of outbreeding depression will be low when populations are relatively recently isolated ( $<500$ years), occupy similar environments, and are of the same karyotype (Frankham et al., 2011).

\section{Promoting Establishment}

Genetic diversity of restoration plantings also may be increased by sowing a high density of seeds or by promoting conditions that maximize plant establishment. Population establishment and/or persistence increases with seeding density during prairie restoration (Grman et al., 2015) and in other plant reintroductions (Godefroid et al., 2011), and this may be due to greater numbers of germinants and/or higher persistence of resulting larger populations given that extinction probabilities decline with increasing colonizing population size (Hurtt \& Pacala, 1995). Furthermore, population size (in concert with population growth rate) is a key determinant of whether populations have enough time to adapt before extinction (Gomulkiewicz \& Holt, 1995; Willi et al., 2006). Species sown with greater density may result in larger populations with more genetic diversity, particularly if mortality is stochastic with respect to genotype. The benefits of sowing a high density of seeds for resulting population genetic diversity may increase if seeds were collected from many environmentally well-matched donor locations (McKay et al., 2005). Moreover, sowing under conditions that maximize plant establishment, such as after fire that exposes mineral soil or during rainy years (Maret \& Wilson, 2005; Groves \& Brudvig, 2019) or introducing soil microorganisms including those necessary for later successional species (Wubs et al., 2016; Koziol et al., 2018), potentially will enhance the genetic diversity resulting from sowing by increasing the resulting population size and increasing the number of genotypes that might establish. For species that do not establish well 


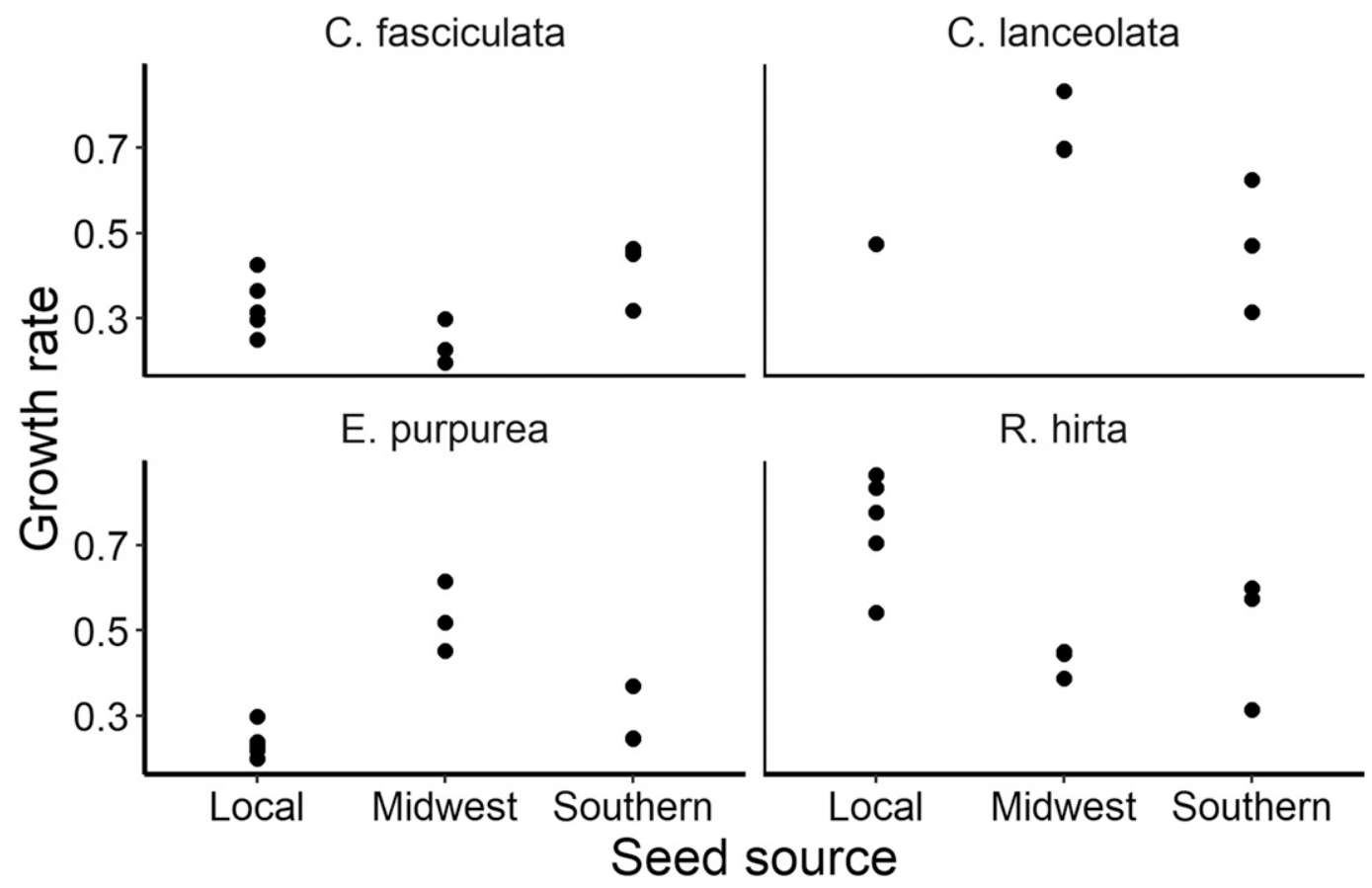

Figure 3. Three seed sources (local, upper Midwestern, and Southern) used in a new restoration experiment manipulating genetic diversity at Kellogg Biological Station, Michigan, differ in key traits such as growth rate when grown in a common greenhouse environment. Four of the study species are shown for example. Local seeds originated from Michigan, northern Indiana, or Ohio. Upper Midwestern seeds were obtained from commercial seed farms from populations originating and grown in Minnesota, Iowa, or Wisconsin, and Southern seeds were obtained from commercial seed farms growing populations originating from Kansas or Missouri. Each datapoint represents a single seedling $(\mathrm{n}=$ one to five seedlings per source per species).

from seed (e.g., owing to low seed viability or exacting germination requirements), propagation and outplanting of seedlings may be an additional method to promote genetically diverse plantings, as transplanted seedling survival can be very high compared to establishment from seed (Gallagher \& Wagenius, 2016).

\section{Maintaining Genetic Variation Through Management}

While the above factors highlight approaches for ensuring that a high genetic diversity population establishes, maintaining genetic variation as the restoration ages may be equally important. Selection, particularly early on in the restoration, may be extremely strong (Kulpa \& Leger, 2013; LaRue et al., 2017) and as a result may erode many of the gains of sowing diverse seed sources. Moreover, because prairie restorations sown from seed undergo succession (Grman et al., 2013) and because natural selection may change dramatically over the course of succession (Scheiner, 1989), those traits favored early in the restoration may not be the most adaptive at later successional stages. For example, in the restored Chamaecrista fasciculata populations mentioned earlier, few observed evolutionary responses (changes in flowering time, root nodule production, and specific leaf area) matched estimates of selection on those traits six years after the prairies had established, which is not necessarily what we would expect to find if the observed trait changes were adaptive (Fig. 2). While it is possible that the observed evolutionary responses are not adaptive and are instead a result of drift, this seems unlikely given the large population sizes. Instead, it is plausible that the observed evolutionary responses reflect the strong selection that occurred early during the restoration (past selection) rather than the selection characteristic of later successional stages (Magnoli, 2018). Given these successional dynamics and their likely effects on selection, factors that promote the maintenance of genetic variation over the course of succession during restoration may be key for maximizing both population establishment and persistence.

We suggest management approaches that may help maintain genetic variation within three main categories: (1) strategies promoting sexual reproduction of established populations including prescribed burning, mowing, and promoting pollination; (2) genetic augmentation through inter-seeding, and (3) promotion of connectivity and gene flow among restorations or between remnant and restored prairies. Interestingly, despite the 
likelihood of increasing genetic diversity, each of these approaches also has the potential to reduce local adaptation either by reducing genetic diversity because they are strong agents of natural selection or through swamping effects of gene flow.

\section{FIRE, MOWING, AND PROMOTING POLLINATORS}

Fire is among the most common management tool in prairies, intended to control invasive and woody species and promote diverse assemblages of native prairie species (Rowe, 2010). Fire can increase plant reproduction in prairies (Old, 1969; Hulbert, 1988), though these effects are not universal across species (e.g., Hartnett, 1991) and details of the prescribed fire regime are important. For example, decisions about when prescribed fire season is implemented have bearing on selection at the community level (Howe, 1994, 1995); similar effects likely operate within species. Yet, any management activity that promotes sexual reproduction either by promoting increased flowering or increased recruitment from seed rather than clonal reproduction should help maintain genetic diversity. Furthermore, the recombination that accompanies sexual reproduction may yield novel genotypes and heighten the benefits of high genetic diversity seed mixes. These benefits may be countered by two forces: (1) the strong selection imposed by fire, and (2) the reduced spatial environmental heterogeneity that sometimes accompanies frequent fires applied at small spatial scales (Collins, 1992). Interestingly, fire applied across larger spatial scales can sometimes increase environmental heterogeneity, which should promote the maintenance of genetic diversity (Fuhlendorf \& Engle, 2004).

Mowing and grazing may produce similar benefits to fire by reducing light competition from dominant grasses, increasing reproduction and increasing opportunities for seed recruitment, at least for some species (e.g., Fahnestock \& Knapp, 1994; Damhoureyeh \& Hartnett, 1997; Martin \& Wilsey, 2006, but see Hickman \& Hartnett, 2002), and grazing may increase environmental heterogeneity through wallowing (bison), trampling, uneven and selective grazing, and nutrient redistribution through waste and carcass decomposition (Knapp et al., 1999). In one case, populations with a stronger grazing intensity exhibited increased genetic variation in plant height compared to ungrazed populations, although no effect of grazing was detected on the genetic variability of five other traits (Völler et al., 2013). However, as with fire, grazing and mowing also may reduce genetic diversity by exerting strong selection on traits such as flowering time or seed size (Völler et al., 2013).

Finally, the benefits of promoting flowering and seed recruitment may be reduced if pollinator availability is low enough to substantially reduce outcrossing.
Ultimately, pollinator abundance may be driven by surrounding land use. In European semi-natural grasslands, pollinators were less abundant in areas surrounded by agricultural lands and this was associated with declines in insect-pollinated plant species (Clough et al., 2014). Yet, in spite of landscape effects, the inclusion of pollinator-attractive species in restoration seed mixes may enhance local pollinator densities (Isaacs et al., 2009) and therefore pollination rates. Common garden experiments have identified candidate species for such efforts (Tuell et al., 2008; Rowe et al., 2018). Likewise, restoration management, such as thinning and burning, will often alter total pollinator abundances, community composition, and richness, sometimes negatively (Potts et al., 2003; Breland et al., 2018), in part by affecting nest sites and influencing floral resource availability (Potts et al., 2003; National Research Council of the National Academies, 2007). As a result, the scale at which disturbances are applied should be carefully considered to allow refuges for pollinators and other taxa (Shuey, 2013).

\section{INTER-SEEDING}

Inter-seeding (also called overseeding) is a restoration approach whereby seeds are sown into an existing restoration. Although more commonly used to increase species diversity of a restoration planting (e.g., Martin \& Wilsey, 2006), it may also lead to genetic augmentation if novel genotypes are added to the population or returned to a population in the event that strong selection during establishment or exceptionally low establishment rates caused genetic bottlenecks that reduced initial genetic diversity. While selection during establishment may be especially strong (Kulpa \& Leger, 2013; LaRue et al., 2017) and while in some cases establishment rates can be extremely low (Grman et al., 2015), there is limited data on the extent to which genetic diversity is eroded during early establishment. In the study of Chamaecrista fasciculata highlighted earlier (Fig. 2), phenotypic variation of restored populations did not differ from variation in the original source population, suggesting genetic diversity may not have been eroded in these populations during establishment (Magnoli, unpublished data). Given the successional dynamics in restored prairies, however, introducing novel genotypes or reintroducing genotypes at later successional stages may introduce traits that may have been disadvantageous early in succession but advantageous at later successional stages.

\section{CONNECTIVITY}

Genetic diversity also can be promoted by careful consideration of restoration locations. Preferentially 
restoring sites near native remnants or in close proximity to other restorations may increase gene flow, which should help maintain or even restore genetic diversity (reviewed in Aavik \& Helm, 2018). For example, connectivity promoted greater recovery of genetic diversity after demographic bottlenecks in an alpine butterfly (Jangjoo et al., 2016), and well-connected populations had higher genetic diversity than more isolated populations of a calcareous grassland plant specialist (DiLeo et al., 2017). Many of the largestscale restorations in the Midwestern United States consider connectivity. For example, 3200 ha of habitat were restored to native prairie and barrens, explicitly to increase connectivity between existing remnants in the Efroymson Restoration at Kankakee Sands, Indiana (Shuey, 2013). However, restorations of such scale and scope may be rare; a recent survey of land managers in the Midwestern United States suggests that few restorations (only 16\%) are located in close proximity to a remnant or restored prairie (Harmon-Threatt \& Chin, 2016).

While both inter-seeding and the promotion of gene flow through landscape connectivity may be likely to increase genetic diversity and necessary in the continuously changing environments driven by successional dynamics in young prairie restorations, a potential cost is that a large influx of novel genotypes may slow the rate of adaptation due to the swamping effects of maladaptive genes (reviewed in Garant et al., 2007). Such effects may be minimal, however, if the strongest selection acts on early demographic stages, thereby eliminating or greatly reducing the influx of maladaptive genes introduced into the population through seed dispersal. Gene flow from pollen dispersal may be more worrisome. Although it can be rare among prairies in even extremely close proximity $(120 \mathrm{~m})$ (Walters, Bauer, and Brudvig, unpublished data), longer-distance pollen dispersal events (e.g., > $200 \mathrm{~m}$ ), can occur for some taxa, particularly when the source population is large and flowering plant diversity and abundance are high in the intervening matrix (e.g., Albrecht et al., 2009). Still, the costs of potential swamping effects of gene flow may be outweighed by the benefits of increased connectivity. Wind-pollinated taxa, with their associated greater pollen dispersal distances, are associated with less differentiation between populations, but also are associated with higher genetic diversity and reduced inbreeding (Hamrick et al., 1979).

\section{Conclusions and Future Directions}

Here we investigated the limits of adaptation in restored prairie populations; however, we still have a limited understanding of the factors inhibiting establishment and persistence of restored populations and when adaptation may be needed for population persistence. While substantial theory on evolutionary rescue and corroborating lab experiments provide clear predictions about when rapid adaptation and evolutionary rescue are most likely to occur (Lynch \& Lande, 1993; Gomulkiewicz \& Holt, 1995; Bell \& Gonzalez, 2009; Gomulkiewicz \& Shaw, 2013), it is not clear how frequently populations in the field, and specifically restored populations, require rescue and how often evolutionary rescue occurs. Such studies are difficult to implement as they require rigorous demographic analyses, combined with approaches from experimental evolution and/or quantitative genetics. However, restorations may be the perfect venues for applying the theory of evolutionary rescue to the field because original source seeds can be saved and used in "resurrection experiments" (sensu Hairston et al., 1999; Franks et al., 2008) that allow for comparing the population growth rates of novel versus "evolved" populations (Magnoli, 2018). Ultimately, restorations could provide opportunities for large-scale experiments manipulating key predictors of evolutionary rescue, such as the amount of standing genetic variation or population size.

Although we may not fully understand when adaptation is necessary for the persistence of prairie populations, it is likely that many restored populations are not well adapted to local site conditions, and as a result factors that promote adaptation should also increase demographic parameters and ultimately population establishment and persistence. One of the biggest gaps in our understanding of the limits of adaptation of such restored ecosystems is the genetic diversity of restored populations, how particular management approaches affect genetic diversity, and how considering effects on genetic diversity might inform where to restore. First, while increasing numbers of studies have compared the genetic diversity of restored populations to wild populations (e.g., Williams \& Davis, 1996; Friar et al., 2000; Aavik et al., 2012; Reynolds et al., 2012), quantifying genetic diversity is no simple task. Neutral genetic diversity may be less relevant to restoration success than quantitative genetic variation in traits underlying adaptation (e.g., Knapp \& Rice, 1998), and identifying traits underlying adaptation is extremely challenging. Ultimately, a full quantitative genetic analysis may be necessary to identify the traits underlying adaptation at a particular site (through phenotypic selection analyses, Lande \& Arnold, 1983) and to determine whether a lack of genetic variation and/or genetic correlations antagonistic to the direction of selection limit evolutionary responses (e.g., Kulpa \& Leger, 2013; Magnoli, 2018). Such studies are time intensive, requiring large numbers of pedigreed individuals; yet, understanding if and when restored populations lack sufficient genetic variation for adaptive 
evolution may inform later management. Such studies are not feasible for every restoration or for every restored population within a restoration, but more studies are needed to identify if and when a lack of genetic variation constrains adaptation of restored populations. Second, as outlined above, management decisions can erode genetic variation if they act as strong selection agents or may help maintain genetic variation if they facilitate reproduction from seed by promoting flowering or seed recruitment (Völler et al., 2013). Yet, studies quantifying these effects, particularly on genetic variation of key functional traits, are exceptionally rare. Finally, by understanding the scales over which gene flow operates among restored prairie patches, managers and land conservancies may be able to make smart decisions about where to restore (e.g., which sorts of landscapes and for which sorts of species) and the extent to which restored prairies can rely on passive (connectivity) versus active (inter-seeding) approaches to maintain genetic diversity over time.

In addition to basic knowledge on the extent to which standing genetic variation may be limited in restored populations, it may also be useful to identify the extent to which trade-offs limit adaptation in restored prairies and to continue identifying methods to promote establishment to ensure large population sizes that have the genetic variation necessary for future adaptation, minimize the swamping effects of gene flow from other nearby populations, and allow time for evolutionary rescue to occur. Evidence from other systems suggests that trade-offs can limit adaptation to human-caused environmental change like global warming (e.g., Etterson \& Shaw, 2001), but there is limited data on whether trade-offs commonly constrain selection acting on restored populations. Critical to these efforts will be identifying key traits affecting population establishment and persistence over succession during restoration.

These knowledge gaps are substantial, but restorations may potentially be so-called "acid tests" (sensu Bradshaw, 1987) of evolutionary theory; few other situations allow for manipulating the genetic composition of experimental populations at such ecologically relevant scales. Reciprocally, understanding how these adaptive processes play out in restored communities also represents the most fruitful avenue for manipulating evolutionary processes to our advantage. While managers likely can do little to overcome coevolutionary constraints, seed mixes can be manipulated to potentially minimize trade-offs and promote genetic diversity, and management approaches can facilitate large population sizes and the maintenance of genetic variation. The demographic benefits of adaptation have made the difference between extinction and persistence and can strongly influence establishment and spread in laboratory studies (e.g., Bell \& Gonzalez, 2009; Szücs et al.,
2017), and in a few greenhouse and field experiments adaptation has had notable effects on population growth rates (Kinnison et al., 2008; Bodbyl Roels \& Kelly, 2011; Magnoli, 2018). It remains to be seen whether management decisions can help the benefits of adaptation be realized in restored populations, yet facilitating adaptation may become increasingly important in the face of global change. Restored populations may not only need to adapt to the novel conditions of the restored area to ensure establishment now, they also may need to adapt to ensure persistence in the warmer, often drier, and more episodic environments that will characterize the future (Davis et al., 2005).

\section{Literature Cited}

Aavik, T. \& A. Helm. 2018. Restoration of plant species and genetic diversity depends on landscape-scale dispersal. Restorat. Ecol. 26: S92-S102.

Aavik, T., P. J. Edwards, R. Holderegger, R. Graf \& R. Billeter. 2012. Genetic consequences of using seed mixtures in restoration: A case study of a wetland plant Lychnis floscuculi. Biol. Conservation 145: 195-204.

Albrecht, M., P. Duelli, M. K. Obrist, D. Kleijn \& B. Schmid. 2009. Effective long-distance pollen dispersal in Centaurea jacea. PLoS One 4: E6751.

Antonovics, J. 1976. The nature of limits to natural selection. Ann. Missouri Bot. Gard. 63: 224-247.

Bakker, J. P. \& F. Berendse. 1999. Constraints in the restoration of ecological diversity in grassland and heathland communities. Trends Ecol. Evol. 14: 63-68.

Basey, A. C., J. B. Fant \& A. T. Kramer. 2015. Producing native plant materials for restoration: 10 rules to collect and maintain genetic diversity. Native Pl. J. 16: 37-53.

Bell, G. \& A. Gonzalez. 2009. Evolutionary rescue can prevent extinction following environmental change. Ecol. Lett. 12: 942-948.

Benayas, J. M. R., A. C. Newton, A. Diaz \& J. M. Bullock. 2009. Enhancement of biodiversity and ecosystem services by ecological restoration: A meta-analysis. Science 325 : 1121-1124.

Bodbyl Roels, S. A. \& J. K. Kelly. 2011. Rapid evolution caused by pollinator loss in Mimulus guttatus. Evolution 65: 2541-2552.

Bradshaw, A. D. 1965. Evolutionary significance of phenotypic plasticity in plants. Adv. Genet. 13: 115-155.

Bradshaw, A. D. 1987. Restoration: An acid test for ecology. Pp. 23-30 in W. R. Jordan III, M. E. Gilpin \& J. D. Aber (editors), Restoration Ecology: A Synthetic Approach to Ecological Research. Cambridge University Press, Cambridge.

Breed, M. F., M. G. Stead, K. M. Ottewell, M. G. Gardner \& A. J. Lowe. 2013. Which provenance and where? Seed sourcing strategies for revegetation in a changing environment. Conservation Genet. 14: 1-10.

Breland, S., N. E. Turley, J. Gibbs, R. Isaacs \& L. A. Brudvig. 2018. Restoration increases bee abundance and richness but not pollination in remnant and post-agricultural woodlands. Ecosphere 9: E02435.

Broadhurst, L. M., A. Lowe, D. J. Coates, S. A. Cunningham, M. McDonald, P. A. Vesk \& C. Yates. 2008. Seed supply for broadscale restoration: Maximizing evolutionary potential. Evol. Appl. 1: 587-597.

Brudvig, L. A., E. Grman, C. W. Habeck, J. L. Orrock \& J. A. Ledvina. 2013. Strong legacy of agricultural land use on soils 
and understory plant communities in longleaf pine woodlands. Forest Ecol. Managem. 310: 944-955.

Bucharova, A., O. Bossdorf, N. Hölzel, J. Kollmann, R. Prasse $\&$ W. Durka. 2019. Mix and match: Regional admixture provenancing strikes a balance among different seedsourcing strategies for ecological restoration. Conservation Genet. 20: 7-17.

Bürger, R. \& M. Lynch. 1995. Evolution and extinction in a changing environment: A quantitative genetic analysis. Evolution 49: 151-163.

Carlson, S. M., C. J. Cunningham \& P. A. H. Westley. 2014. Evolutionary rescue in a changing world. Trends Ecol. Evol. 29: 521-530.

Clough, Y., J. Ekroos, A. Báldi, P. Batáry, R. Bommarco, N. Gross, A. Holzschuh, et al. 2014. Density of insectpollinated grassland plants decreases with increasing surrounding land-use intensity. Ecol. Lett. 17: 1168-1177.

Collins, S. L. 1992. Fire frequency and community heterogeneity in tallgrass prairie vegetation. Ecology 73: 2001-2006.

Conner, J. K. 2012. Quantitative genetic approaches to evolutionary constraint: How useful? Evolution 66: 3313-3320.

Damhoureyeh, S. A. \& D. C. Hartnett. 1997. Effects of bison and cattle on growth, reproduction, and abundances of five tallgrass prairie forbs. Amer. J. Bot. 84: 1719-1728.

Davis, M. B., R. G. Shaw \& J. R. Etterson. 2005. Evolutionary responses to changing climate. Ecology 86: 1704-1714.

de Mazancourt, C., E. Johnson \& T. G. Barraclough. 2008. Biodiversity inhibits species' evolutionary responses to changing environments. Ecol. Lett. 11: 380-388.

Des Marais, D. L., K. M. Hernandez \& T. E. Juenger. 2013. Genotype-by-environment interaction and plasticity: Exploring genomic responses of plants to the abiotic environment. Annu. Rev. Ecol. Evol. Syst. 44: 5-29.

DiLeo, M. F., Y. Rico, H. J. Boehmer \& H. H. Wagner. 2017. An ecological connectivity network maintains genetic diversity of a flagship wildflower, Pulsatilla vulgaris. Biol. Conservation 212: 12-21.

Dyer, A. R., E. E. Knapp \& K. J. Rice. 2016. Unintentional selection and genetic changes in native perennial grass populations during commercial seed production. Ecol. Res. 34: 39-48.

Ellstrand, N. C. \& K. A. Schierenbeck. 2000. Hybridization as a stimulus for the evolution of invasiveness in plants? Proc. Natl. Acad. Sci. U.S.A. 97: 7043-7050.

Ensslin, A., A. Van de Vyver, T. Vanderborght \& S. Godefroid. 2018. Ex situ cultivation entails high risk of seed dormancy loss on short-lived wild plant species. J. Appl. Ecol. 55: 1145-1154.

Etterson, J. R. \& R. G. Shaw. 2001. Constraint on adaptive evolution in response to global warming. Science 294: 151-154.

Fahnestock, J. T. \& A. K. Knapp. 1994. Plant responses to selective grazing by bison: Interactions between light, herbivory, and water stress. Vegetatio 115: 123-131.

Frankham, R., J. D. Ballou, M. D. B. Eldridge, R. C. Lacy, K. Ralls, M. R. Dudash \& C. B. Fenster. 2011. Predicting the probability of outbreeding depression. Conservation Biol. 25: 465-475.

Franks, S. J., J. C. Avise, W. E. Bradshaw, J. K. Conner, J. R. Etterson, S. J. Mazer, R. G. Shaw, et al. 2008. The resurrection initiative: Storing ancestral genotypes to capture evolution in action. BioScience 58: 870-873.

Friar, E. A., T. Ladoux, E. H. Roalson \& R. H. Robichaux. 2000. Microsatellite analysis of a population crash and bottleneck in the Mauna Kea silversword, Agryoxiphium sandwicense ssp. sandwicense (Asteraceae), and its implications for reintroduction. Molec. Ecol. 9: 2027-2034.
Fuhlendorf, S. D. \& D. M. Engle. 2004. Application of the firegrazing interaction to restore a shifting mosaic on tallgrass prairie. J. Appl. Ecol. 41: 604-614.

Gallagher, M. K. \& S. Wagenius. 2016. Seed source impacts germination and early establishment of dominant grasses in prairie restorations. J. Appl. Ecol. 54: 251-263.

Garant, D., S. E. Forde \& A. P. Hendry. 2007. The multifarious effects of dispersal and gene flow on contemporary adaptation. Funct. Ecol. 21: 434-443.

Godefroid, S., C. Piazza, G. Rossi, S. Buord, A.-D. Stevens, R. Aguraiuja, C. Cowell, et al. 2011. How successful are plant species reintroductions? Biol. Conservation 144: 672-682.

Gomulkiewicz, R. \& R. D. Holt. 1995. When does evolution by natural selection prevent extinction? Evolution 49: 201-207.

Gomulkiewicz, R. \& R. G. Shaw. 2013. Evolutionary rescue beyond the models. Philos. Trans. Roy. Soc. London 368: 20120093.

Grman, E., T. Bassett \& L. A. Brudvig. 2013. Confronting contingency in restoration: Management and site history determine outcomes of assembling prairies, but site characteristics and landscape context have little effect. J. Appl. Ecol. 50: 1234-1243.

Grman, E., L. A. Brudvig \& T. Bassett. 2014. A prairie plant community dataset for addressing questions in community assembly and restoration. Ecology 95: 2363.

Grman, E., T. Bassett, C. R. Zirbel \& L. A. Brudvig. 2015. Dispersal and establishment filters influence the assembly of restored prairie plant communities. Restorat. Ecol. 23: 892-899.

Groves, A. M. \& L. A. Brudvig. 2019. Interannual variation in precipitation and other planting conditions impacts seedling establishment in sown plant communities. Restorat. Ecol. 27: 128-137.

Hairston, N. G., Jr., S. P. Ellner, M. A. Geber, T. Yoshida \& J. A. Fox. 2005. Rapid evolution and the convergence of ecological and evolutionary time. Ecol. Lett. 8: 1114-1127.

Hairston, N. G., W. Lampert, C. E. Caceres, C. L. Holtmeier, L. J. Weider, U. Gaedke, J. M. Fishcher, et al. 1999. Lake ecosystems: Rapid evolution revealed by dormant eggs. Nature 401: 446.

Hamrick, J. L., Y. B. Linhart \& J. B. Mitton. 1979. Relationships between life history characteristics and electrophoretically detectable genetic variation in plants. Ann. Rev. Ecol. Syst. 10: 173-200.

Harmon-Threatt, A. \& K. Chin. 2016. Common methods for tallgrass prairie restoration and their potential effects on bee diversity. Nat. Areas J. 36: 400-411.

Hartnett, D. C. 1991. Effects of fire in tallgrass prairie on growth and reproduction of prairie coneflower (Ratibida columnifera: Asteraceae). Amer. J. Bot. 78: 429-435.

Hendry, A. P., M. T. Kinnison, M. Heino, T. Day, T. B. Smith, G. Fitt, C. T. Bergstrom, et al. 2011. Evolutionary principles and their practical application. Evol. Appl. 4: 159-183.

Herms, D. A. \& W. J. Mattson. 1992. The dilemma of plants: To grow or defend. Quart. Rev. Biol. 67: 283-335.

Hickman, K. R. \& D. C. Hartnett. 2002. Effects of grazing intensity on growth, reproduction, and abundance of three palatable forbs in Kansas tallgrass prairie. Pl. Ecol. 159: 23-33.

Hobbs, R. J., E. Higgs \& J. A. Harris. 2009. Novel ecosystems: Implications for conservation and restoration. Trends Ecol. Evol. 24: 599-605.

Honnay, O. \& H. Jacquemyn. 2007. Susceptibility of common and rare plant species to the genetic consequences of habitat fragmentation. Conservation Biol. 21: 823-831. 
Howe, H. F. 1994. Response of early- and late-flowering plants to fire season in experimental prairies. Ecol. Appl. 4: 121-133.

Howe, H. F. 1995. Succession and fire season in experimental prairie plantings. Ecology 76: 1917-1925.

Hulbert, L. C. 1988. Causes of fire effects in tallgrass prairie. Ecology 69: 46-58.

Hurtt, C. G. \& S. W. Pacala. 1995. The consequences of recruitment limitation: Reconciling chance, history and competitive differences between plants. J. Theor. Biol. 176: $1-12$.

Isaacs, R., J. Tuell, A. Fiedler, M. Gardiner \& D. Landis. 2009. Maximizing arthropod-mediated ecosystem services in agricultural landscapes: The role of native plants. Frontiers Ecol. Environm. 7: 196-203.

Jangjoo, M., S. F. Matter, J. Roland \& N. Keyghobadi. 2016. Connectivity rescues genetic diversity after a demographic bottleneck in a butterfly population network. Proc. Natl. Acad. Sci. U.S.A. 113: 10914-10919.

Jones, E. I. \& R. Gomulkiewicz. 2012. Biotic interactions, rapid evolution, and the establishment of introduced species. Amer. Naturalist 179: E28-E36.

Kinnison, M. T., M. J. Unwin \& T. P. Quinn. 2008. Ecoevolutionary vs. habitat contributions to invasion in salmon: Experimental evaluation in the wild. Molec. Ecol. 17: 405-414.

Kleynhans, E. J., S. P. Otto, P. B. Reich \& M. Vellend. 2016. Adaptation to elevated $\mathrm{CO}_{2}$ in different biodiversity contexts. Nat. Commun. 7: 12358.

Knapp, A. K., J. M. Blair, J. M. Briggs, S. L. Collins, D. C. Hartnett, L. C. Johnson \& E. G. Towne. 1999. The keystone role of bison in North American tallgrass prairie: Bison increase habitat heterogeneity and alter a broad array of plant, community, and ecosystem processes. BioScience 49: 39-50.

Knapp, E. E. \& K. J. Rice. 1998. Comparison of isozymes and quantitative traits for evaluating patterns of genetic variation in purple needlegrass (Nassella pulchra). Conservation Biol. 12: 1031-1041.

Koziol, L., P. A. Schultz, G. L. House, J. T. Bauer, E. L. Middleton \& J. D. Bever. 2018. The plant microbiome and native plant restoration: The example of native mycorrhizal fungi. BioScience 68: 996-1006.

Kramer, A. T., B. Crane, J. Downing, J. L. Hamrick, K. Havens, A. Highland, S. K. Jacobi, et al. 2019. Sourcing native plants to support ecosystem function in different planting contexts. Restorat. Ecol. 27: 470-476.

Kulpa, S. M. \& E. A. Leger. 2013. Strong natural selection during plant restoration favors an unexpected suite of plant traits. Evol. Appl. 3: 510-523.

Lande, R. \& S. J. Arnold. 1983. The measurement of selection on correlated characters. Evolution 37: 1210-1226.

LaRue, E. A., S. M. Chambers \& N. C. Emery. 2017. Ecoevolutionary dynamics in restored communities and ecosystems. Restorat. Ecol. 25: 19-26.

Leimu, R. \& M. Fischer. 2008. A meta-analysis of local adaptation in plants. PLoS One 3: E4010.

Lesica, P. \& F. W. Allendorf. 1999. Ecological genetics and the restoration of plant communities: Mix or match? Restorat. Ecol. 7: 42-50.

Lynch, M. \& R. Lande. 1993. Evolution and extinction in response to environmental change. Pp. 234-250 in P. Kareiva, J. Kingsolver \& R. Huey (editors), Biotic Interactions and Global Change. Sinauer Associates, Inc., Sunderland, Massachusetts.

Magnoli, S. M. 2018. The Role of Rapid Adaptation in Plant Population Establishment. Ph.D. Thesis. Michigan State University, East Lansing.
Maret, M. P. \& M. V. Wilson. 2005. Fire and litter effects on seedling establishment in western Oregon upland prairies. Restorat. Ecol. 13: 562-568.

Martin, L. M. \& B. J. Wilsey. 2006. Assessing grassland restoration success: Relative roles of seed additions and native ungulate activities. J. Appl. Ecol. 43: 1098-1109.

Matthews, J. W. \& G. R. Spyreas. 2010. Convergence and divergence in plant community trajectories as a framework for monitoring wetland restoration progress. J. Appl. Ecol. 47: 1128-1136.

McKay, J. K., C. E. Christian, S. Harrison \& K. J. Rice. 2005. "How local is local?"- A review of practical and conceptual issues in the genetics of restoration. Restorat. Ecol. 13: 432-440.

McLauchlan, K. 2006. The nature and longevity of agricultural impacts on soil carbon and nutrients: A review. Ecosystems 9: 1364-1382.

Nagel, R., W. Durka, O. Bossdorf \& A. Bucharova. 2019. Rapid evolution in native plants cultivated for ecological restoration: Not a general pattern. Pl. Biol. 21(3): 551-558.

National Research Council of the National Academies. 2007. Strategies for maintaining pollinators and pollination services. Pp. 155-195 in Status of Pollinators in North America. The National Academies Press, Washington, D.C.

Norton, D. A. 2009. Species invasions and the limits to restoration: Learning from the New Zealand experiences. Science 325: 569-571.

Old, S. M. 1969. Microclimate, fire, and plant production in an Illinois prairie. Ecol. Monogr. 39: 355-384.

Palumbi, S. R. 2001. Humans as the world's greatest evolutionary force. Science 293: 1786-1790.

Potts, S. G., B. Vulliamy, A. Dafni, G. Ne'eman, C. O'Toole, S. Roberts \& P. Willmer. 2003. Response of plant-pollinator communities to fire: Changes in diversity, abundance and floral reward structure. Oikos 101: 103-112.

Prober, S. M., M. Byrne, E. H. McLean, D. A. Steane, B. M. Potts, R. E. Vaillancourt \& W. D. Stock. 2015. Climateadjusted provenancing: A strategy for climate-resilient ecological restoration. Frontiers Ecol. Evol. 3: 65.

Reynolds, L. K., M. Waycott, K. J. McGlathery, R. J. Orth \& J. C. Zieman. 2012. Eelgrass restoration by seed maintains genetic diversity: Case study from a coastal bay system. Mar. Ecol. Progr. Ser. 448: 223-233.

Rice, K. J. \& N. C. Emery. 2003. Managing microevolution: Restoration in the face of global change. Frontiers Ecol. Environ. 1: 469-478.

Richardson, J. L., M. C. Urban, D. I. Bolnick \& D. K. Skelly. 2014. Microgeographic adaptation and the spatial scale of evolution. Trends Ecol. Evol. 29: 165-176.

Rius, M. \& J. A. Darling. 2014. How important is intraspecific genetic admixture to the success of colonizing populations? Trends Ecol. Evol. 29: 233-242.

Rowe, C. L. J. \& E. A. Leger. 2011. Competitive seedlings and inherited traits: A test of rapid evolution of Elymus multisetus (big squirreltail) in response to cheatgrass invasion. Evol. Appl. 4: 485-498.

Rowe, C. L. J. \& E. A. Leger. 2012. Seed source affects establishment of Elymus multisetus in postfire revegetation in the Great Basin. W. N. Amer. Naturalist 72: 543-553.

Rowe, H. I. 2010. Tricks of the trade: Techniques and opinions from 38 experts in tallgrass prairie restoration. Restorat. Ecol. 18: 253-262.

Rowe, L., D. Gibson, D. Landis, J. Gibbs \& R. Isaacs. 2018. A comparison of drought-tolerant prairie plants to support managed and wild bees in conservation programs. Environm. Entomol. 47: 1128-1142. 
Samson, F. \& F. Knopf. 1994. Prairie conservation in North America. BioScience 44: 418-421.

Scheiner, S. M. 1989. Variable selection along a successional gradient. Evolution 43: 548-562.

Schoener, T. W. 2011. The newest synthesis: Understanding the interplay of evolutionary and ecological dynamics. Science 331: 426-429.

Schröder, R. \& R. Prasse. 2013. Cultivation and hybridization alter the germination behavior of native plants used in revegetation and restoration. Restorat. Ecol. 21: 793-800.

Sgrò, C. M., A. J. Lowe \& A. A. Hoffmann. 2011. Building evolutionary resilience for conserving biodiversity. Evol. Appl. 4: 326-337.

Shuey, J. A. 2013. Habitat re-Creation (ecological restoration) as a strategy for conserving insect communities in highly fragmented landscapes. Insects 4: 761-780.

Strauss, S. Y. 2014. Ecological and evolutionary responses in complex communities: Implications for invasions and ecoevolutionary feedbacks. Oikos 123: 257-266.

Suding, K. N. 2011. Toward an era of restoration ecology. Successes, failures, and opportunities ahead. Annu. Rev. Ecol. Evol. Syst. 42: 465-487.

Szücs, M., M. L. Vahsen, B. A. Melbourne, C. Hoover, C. Weiss-Lehman \& R. A. Hufbauer. 2017. Rapid adaptive evolution in novel environments acts as an architect of population range expansion. Proc. Natl. Acad. Sci. U.S.A. 114: 13501-13506.

Török, P., V. Eniko, B. Deák, S. Lengyel \& B. Tóthmérész. 2011. Grassland restoration on former croplands in Europe:
An assessment of applicability of techniques and costs. Biodivers. \& Conservation 11: 2311-2332.

Tuell, J. K., A. K. Fiedler, D. Landis \& R. Isaacs. 2008. Visitation by wild and managed bees (Hymenoptera: Apoidea) to Eastern U.S. native plants for use in conservation programs. Environm. Entomol. 37: 707-718.

Vander Mijnsbrugge, K., A. Bischoff \& B. Smith. 2010. A question of origin: Where and how to collect seed for ecological restoration. Basic Appl. Ecol. 11: 300-311.

Völler, E., H. Auge, O. Bossdorf \& D. Prati. 2013. Land use causes genetic differentiation of life-history traits in Bromus hordaceus. Global Change Biol. 19: 892-899.

Willi, Y., J. Van Buskirk \& A. A. Hoffmann. 2006. Limits to the adaptive potential of small populations. Annu. Rev. Ecol. Evol. Syst. 37: 433-458.

Williams, S. L. \& C. A. Davis. 1996. Population genetic analyses of transplanted eelgrass (Zostera marina) beds reveal reduced genetic diversity in southern California. Restorat. Ecol. 4: 163-180.

Wise, M. J. \& M. D. Rausher. 2013. Evolution of resistance to a multiple-herbivore community: Genetic correlations, diffuse coevolution, and constraints on the plant's response to selection. Evolution 67: 1767-1779.

Wubs, E. R., W. H. van der Putten, M. Bosch \& T. M. Bezemer. 2016. Soil inoculation steers restoration of terrestrial ecosystems. Nat. Pl. 2: 16107

Züst, T. \& A. A. Agrawal. 2017. Trade-offs between plant growth and defense against insect herbivory: An emerging mechanistic synthesis. Annu. Rev. Pl. Biol. 28: 513-534. 